\title{
Light can ameliorate low mood in healthy people
}

\author{
Takeshi Terao • Nobuhiko Hoaki
}

Received: 27 September 2010 / Accepted: 30 September 2010 /Published online: 12 October 2010

(C) Springer-Verlag 2010

We greatly appreciate Emeritus Professor Kripke for his interest in our recent article (Hoaki et al. 2010) where it was revealed that higher illuminance of daytime, greater fluctuation in sleep time, and lower central serotonergic function significantly and independently predicted hyperthymic tendency.

In response to the inquiry from Emeritus Professor Kripke, we investigated the association between illuminance of daytime and Hamilton depression rating scale (HAM-D) scores and that between illuminance of daytime and Young mania rating scale (YMRS) scores. As a result, there was a significantly negative association between illuminance of daytime and Hamilton depression rating scale scores (rho $=-0.23, p=0.035$ ), but no significant association between illuminance of daytime and YMRS. It should be noted that our subjects were healthy volunteers, and their range of HAM-D and YMRS was $0-6$ and $0-4$, respectively. Therefore, these scores were within normal limits. Nonetheless, the significantly negative association between illuminance of daytime and HAM-D scores indicate that light can ameliorate low mood in healthy people. These findings are in accordance with the report from Kripke's group (Espiritu et al. 1994). Further studies are required to prospectively investigate whether light can prevent the occurrence of depression in healthy people.

\section{References}

Espiritu RC, Kripke DF, Ancoli-Israel S, Mowen MA, Mason WJ, Fell RL, Klauber MR, Kaplan OJ (1994) Low illumination experienced by San Diego adults: association with atypical depressive symptoms. Biol Psychiatry 35:403-407

Hoaki N, Terao T, Wang Y, Goto S, Tsuchiyama K, Iwata N (2010) Biological aspect of hyperthymic temperament: light, sleep, and serotonin. Psychopharmacology. doi:10.1007/s00213-010-1999-0

T. Terao $(\bowtie) \cdot N$. Hoaki

Oita University Faculty of Medicine,

Yufu, Japan

e-mail: terao@med.oita-u.ac.jp 